\title{
Hubungan Gaya Kelekatan Dengan Self-Efficacy Akademik Siswa SMA Di Jakarta
}

\author{
Raysita Nilam Sari \\ Fakultas Psikologi, Universitas YARSI \\ nilamsari.raysita@gmail.com \\ Sari Zakiah Akmal \\ Fakultas Psikologi, Universitas YARSI \\ sari.zakiah@yarsi.ac.id
}

\begin{abstract}
Abstrak
Masalah remaja siswa SMA yang sering terjadi dalam akademik, yaitu cara belajar yang tidak efektif, penyelesaian tugas-tugas dan latihan, pencarian serta penggunaan sumber belajar, kesulitan belajar, kurangnya kosentrasi dalam belajar dan banyaknya tuntutan yang lebih besar dalam akademik. Pada permasalahan yang terjadi, peneliti melakukan survei kepada 30 siswa SMA dan hasilnya menunjukkan $60 \%$ dari 30 siswa SMA memiliki self-efficacy akademik dengan kategori yang rendah. Faktor-faktor dari self-efficacy akademik yaitu keluarga, lingkungan dan sekolah. Kelekatan dapat mempengaruhi salah satunya selfefficacy yang penting untuk keberhasilan akademik. Penelitian dilakukan dengan penyebaran skala gaya kelekatan dan skala self-efficacy akademik kepada 247 siswa SMA di Jakarta. Hasil penelitian menunjukkan bahwa terdapat hubungan positif signifikan antara gaya kelekatan secure ataachment dengan self-efficacy akademik siswa SMA $(\mathrm{r}=0,130$ dan $\mathrm{p}=0,040)$. Selain itu terdapat hubungan negatif signifikan pada gaya kelekatan fearful-avoidant attachment dengan selfefficacy akademik pada siswa SMA $(r=-0,198$ dan $\mathrm{p}=0,002)$.
\end{abstract}

Kata kunci : remaja, self- efficacy akademik, gaya kelekatan

\section{Pendahuluan}

Siswa SMA merupakan kelompok remaja yang mengalami gejala krisis. Gejala krisis tersebut antara lain kurangnya perhatian siswa pada waktu pelajaran, kelalaian dalam mengerjakan tugas atau pekerjaan rumah, belajar hanya ketika ulangan atau ujian, dan memiliki pandangan untuk lulus pada saat ujian (Nugrahani, 2010). Permasalahan lain yang terjadi pada remaja adalah tuntutan yang lebih besar dalam tugas akademik. Menurut Woolfolk (1990) tugas akademik adalah pekerjaan yang harus dipenuhi oleh siswa untuk mengasah 
kemampuannya. Beberapa dari tugas akademik terdapat sejumlah tuntutan tertentu yang menuntut siswa untuk menghafal, membuat suatu kesimpulan, menganalisa, menggolongkan, ataupun menerapkannya dalam kehidupan sehari-hari. Sebagian besar siswa merasa yakin dengan kemampuan dirinya dan sebagian siswa tidak yakin dengan kemampuan dirinya dalam memenuhi tuntutan tugas akademik. Dalam psikologi, kepercayaan akan kemampuan diri disebut self-efficacy.

Peneliti telah melakukan survey kepada 30 siswa SMA di Jakarta dengan menggunakan kuesioner self-efficacy akademik untuk mengetahui gambaran selfefficacy akademik pada siswa. Subyek yang digunakan peneliti untuk melakukan survey ini adalah siswa SMA kelas X, XI, dan XII. Hasil yang diperoleh dari survey ini adalah $60 \%$ dari 30 siswa SMA memiliki self-efficacy akademik dengan kategori yang rendah. Hal ini menunjukkan bahwa self-efficacy akademik siswa cenderung rendah, sehingga penting untuk diteliti lebih lanjut.

Self-efficacy dalam setting akademik atau self-efficacy akademik adalah keyakinan yang dimiliki seseorang tentang kemampuan atau kompetensinya untuk mengerjakan tugas, mencapai tujuan, dan mengatasi tantangan akademik (Bandura dalam Dwitantyanov,dkk 2010). Menurut Zajacova, dkk (2005) selfefficacy akademik merupakan keyakinan mahasiswa terhadap kemampuan mereka dalam melaksanakan tugas-tugas akademik seperti mempersiapkan diri untuk ujian dan menyusun makalah. Semakin tinggi self-efficacy akademik, maka semakin tinggi prestasi akademik seseorang (Ferla, Valcke, \& Cai, 2007). Individu yang menganggap tingkat self-efficacy akademik cukup tinggi akan berusaha lebih keras, berprestasi lebih banyak, dan lebih gigih dalam menjalankan tugas dengan menggunakan keterampilan yang dimiliki daripada yang menganggap self-efficacy akademiknya rendah.

Schunk dan Meece (2006) mengatakan bahwa self-efficacy akademik memiliki faktor yang sama dengan self-efficacy yaitu keluarga, sekolah, dan lingkungan. Pengaruh yang terkait dari masing-masing faktor tersebut memiliki efek mendalam pada keyakinan remaja tentang kemampuan mereka untuk berhasil masuk dan keluar dari sekolah. Keluarga merupakan keseluruhan yang kompleks yang terdiri atas bagian-bagian yang saling berhubungan dan berinteraksi 
(Santrock, 2011). Segala bentuk interaksi antara orangtua terhadap bayinya akan menjadi suatu pengalaman bagi bayi, yang dikatakan oleh Ainsworth akan berkembang menjadi sebuah hubungan kelekatan. Kelekatan dapat mempengaruhi self-efficacy, self-confidence, dan self-esteem yang semuanya penting untuk keberhasilan akademik.

Bartholomew dan Horowitz (1991) menyatakan teori yang cukup berbeda dibandingkan tokoh-tokoh sebelumnya dengan mengemukakan dua konsep dari gaya kelekatan, yaitu model of self dan model of others. Model of self adalah pandangan mengenai diri sendiri apakah menjadi sosok yang dapat memberikan dukungan dan perlindungan. Sedangkan model of others adalah pandangan mengenai apakah figur lekat (orang lain) merupakan sosok yang dapat memberikan dukungan dan perlindungan. Kedua dimensi tersebut memiliki penilaian yang positif (mendukung dan memberikan perlindungan) dan negatif (mengabaikan dan tidak memberikan perlindungan). Interaksi kedua dimensi tersebut dapat memunculkan empat dimensi gaya kelekatan, yaitu: secure attachment (kelekatan aman), preoccupied attachment (terikat), dismissing attachment (lepas), dan fearful-avoidant attachment (cemas).

Individu yang memiliki secure attachment memiliki model of self yang positif dan model of other nyaman dalam menjalin hubungan interpersonal. Pada masa remaja/dewasa, gaya kelekatan aman akan mengembangkan pandangan yang positif terhadap diri dan orang lain. Individu dengan kelekatan aman akan mudah akrab dengan orang asing, memiliki pandangan yang positif terhadap orang lain, memiliki kepercayaan diri dan konsep diri yang baik serta cenderung berpikir realistis (Bartholomew dan Horowitz, 1991).

Menurut Bartholomew dan Horowitz (1991), individu yang termasuk dalam preoccupied attachment memiliki model of self negatif dan model of other bergantung kepada orang lain. Dengan demikian, individu tersebut cenderung tidak mudah berbagi pemikiran dan perasaan pada orang lain. Mereka menunjukkan ketidakmampuan untuk membuka diri pada dunia luar, sehingga kurang mampu mengungkapkan perasaan dan pemikiran yang ada dalam dirinya. 
Seseorang dengan dismissing attachment memiliki model of self merasa nyaman dengan kemandirian dan model of other membatasi interaksi dengan orang lain. Individu ini melihat dirinya sebagai seseorang yang berharga, mandiri, sedangkan orang lain melihat mereka secara negatif dan mendeskripsikan mereka sebagai seorang yang tidak ramah dan memiliki keterampilan sosial yang terbatas (Bartholomew dan Horowitz, 1991).

Seseorang dengan fearful attachment memiliki model of self meragukan diri sendiri dan memiliki model of other kesulitan untuk mempercayai orang lain. Fearful attachment juga diasosiasikan dengan hubungan interpersonal yang negatif. Pada masa remaja / dewasa, gaya kelekatan ini akan mengembangkan berbagai kecemasan terhadap diri dan orang lain. Hal ini terlihat pada karakteristik seperti mudah khawatir jika temannya tidak menyukai dirinya, individu seringkali berpikir bahwa orang lain tidak menyukai dan merasa ketakutan jika ditinggalkan atau diabaikan orang lain (Bartholomew dan Horowitz, 1991).

Berdsarkan pemaparan di atas, diketahui bahwa self-efficacy memiliki peran penting untuk keberhasilan akademik pada remaja. Perkembangan selfefficacy dipengaruhi oleh gaya kelekatan. Pengaruh yang terkait seperti kenyamanan di lingkungan sekolah, keluarga dapat meningkatkan self-efficacy akademik dan gaya kelekatan yang dominan dapat muncul sesuai dengan situasi yang dibutuhkan. Tujuan dari penelitian ini adalah untuk mengetahui hubungan dimensi-dimensi gaya kelekatan dengan self-efficacy akademik. Manfaat penelitian ini secara teoritis diharapkan dapat memperkaya penelitian di bidang psikologi terutama berkaitan dengan gaya kelekatan orangtua terkhusus pada topik gaya kelekatan orangtua dan self-efficacy akademik. Selain itu, diharapkan penelitian ini juga dapat memberikan pengetahuan mengenai bagaimana hubungan gaya kelekatan orangtua dengan self-efficacy akademik siswa SMA serta menjadi bahan pertimbangan bagi penelitian-penelitian selanjutnya dan secara praktis dapat diterapkan oleh siswa, orangtua, dan institusi pendidikan sebagai salah satu intervensi terhadap gaya kelekatan untuk meningkatkan selfefficacy akademik. 


\section{Metode}

Penelitian ini dengan metode penelitian kuantitatif dengan rancangan penelitian asosiatif dan jenis penelitian ini adalah non-eksperimental dan korelasional. Variabel 1 dalam penelitian ini yaitu gaya kelekatan (Attachment Style) yang diukur dengan menggunakan skala Attachment Style Questionnaire (ASQ) yang disusun oleh Hofstra dan Van Oudenhoven (2004). Instrumen ASQ berbentuk kuesioner yang terdiri dari 22 pernyataan yang tersebar dalam empat dimensi, yaitu: 5 aitem mengukur gaya kelekatan secure $(\alpha=0.765), 5$ aitem mengukur gaya kelekatan fearful avoidance $(\alpha=0.702), 7$ aitem mengukur gaya kelekatan preooccupaid $(\alpha=0.843)$ dan 5 aitem mengukur gaya kelekatan dismissing $(\alpha=0.761)$. Kemudian variabel 2 dalam penelitian ini yaitu selfefficacy akademik menggunakan skala Academic Self-Efficacy Scale yang disusun oleh Zajacova, dkk (2005) yang telah diadaptasi oleh Rauf (2015). Instrumen Academic Self-Efficacy Scale berbentuk kuesioner yang terdiri dari 27 pernyataan dengan koefisien reliabilitas $(\alpha) 0.963$.

Populasi penelitian ini adalah siswa SMA yang ada di Wilayah Jakarta dengan sampel sebanyak 247 siswa SMA. Teknik pengambilan sampel penelitian ini menggunakan non-probability sampling yang digunakan adalah incidental sampling. Hipotesa penelitian dibuktikan dengan menggunakan teknik analisa statistik korelasi spearman rank karena data variabel Self-Efficacy Akademik tidak terdistribusi normal $(\mathrm{KZ}=1.401, \mathrm{p}=0.039)$

\section{Hasil dan Pembahasan}

\section{Demografis Responden}

Berikut ini adalah deskripsi data demografis sampel penelitian.

Tabel 1. Demografi Responden Penelitian

\begin{tabular}{lll}
\hline Variabel & Jumlah & Presentase \\
\hline Jenis Kelamin & & \\
Laki-Laki & 72 & $29,1 \%$ \\
Perempuan & 175 & $70,9 \%$ \\
Usia (mean= & 16,65 tahun) & \\
$14-17$ tahun & 213 & $86,2 \%$ \\
$18-21$ tahun & 34 & $13,8 \%$ \\
\multicolumn{2}{l}{ Wilayah Sekolah } & \\
Jakarta Barat & 26 & $10,5 \%$ \\
\hline
\end{tabular}

Jurnal Insight Fakultas Psikologi Universitas Muhammadiyah Jember | 41 


\begin{tabular}{lll}
\hline Jakarta Pusat & 47 & $19,0 \%$ \\
Jakarta Selatan & 14 & $5,7 \%$ \\
Jakarta Timur & 142 & $57,5 \%$ \\
Jakarta Utara & 18 & $7,3 \%$ \\
Kelas & & \\
10 & 52 & $21,1 \%$ \\
11 & 37 & $15,0 \%$ \\
12 & 158 & $64,0 \%$ \\
Jurusan & & \\
IPA & 118 & $47,8 \%$ \\
IPS & 129 & $52,2 \%$ \\
\hline
\end{tabular}

Mayoritas partisipan dalam penelitian ini berjenis kelamin perempuan $(70,9 \%)$ dan berusia antara $14-17$ tahun (86,2\%). Mayoritas responden bersekolah di wilayah Jakarta Timur (57,5\%) duduk di bangku SMA kelas 12 $(64,0 \%)$ dan berasal dari jurusan IPS (52,2\%).

\section{Kategorisasi Gaya Kelakatan}

Tabel 2. Nilai Statistik Skala Gaya Kelekatan

\begin{tabular}{ccccc}
\hline & $\begin{array}{c}\text { Skor } \\
\text { Terendah }\end{array}$ & $\begin{array}{c}\text { Skor } \\
\text { Tertinggi }\end{array}$ & $\begin{array}{c}\text { Nilai } \\
\text { Rata-rata }\end{array}$ & $\begin{array}{c}\text { Standar } \\
\text { Deviasi }\end{array}$ \\
\hline Gaya Kelekatan & & & & \\
Secure Attachment & 11 & 28 & 20,69 & 2,64 \\
Fearful-avoidant Attachment & 7 & 20 & 13,57 & 2,65 \\
Preoccupied Attachment & 11 & 28 & 20,28 & 3,32 \\
Dismissing Attachment & 6 & 20 & 13,25 & 2,54 \\
\hline
\end{tabular}

Diketahui skor terendah gaya kelekatan perdimensi adalah untuk secure attachment skor terendah 11 dan skor tertinggi 28 dengan nilai rata-rata 20,69 dan standar deviasi 2,64. Fearful-avoidant attachment skor terendah 7 dan skor tertinggi 20 dengan nilai rata-rata 13,57 dan standar deviasi 2,65. Preoccupied Attachment skor terendah 11 dan skor tertinggi 28 dengan nilai rata-rata 20,28 dan standar deviasi 3,32. Dismissing attachment skor terendah 6 dan skor tertinggi 20 dengan nilai rata-rata 13,25 dan standar deviasi 2,54. Sementara itu, skor terendah self-efficacy akademik 31 dan skor tertinggi 250 dengan nilai rata-rata 181,81 dan standar deviasi 39,44.

Dalam penelitian ini untuk mengetahui dimensi gaya kelekatan yang paling dominan, dilihat dari total skor pada subjek penelitian yang dikonversikan menjadi Z- score. Z-score tertinggi menunjukkan dimensi gaya kelekatan yang 
paling dominan dimiliki subjek. Hasil Z-score pada subjek penelitian sebagai berikut:

Gambar 1. Hasil Perhitungan Z-score

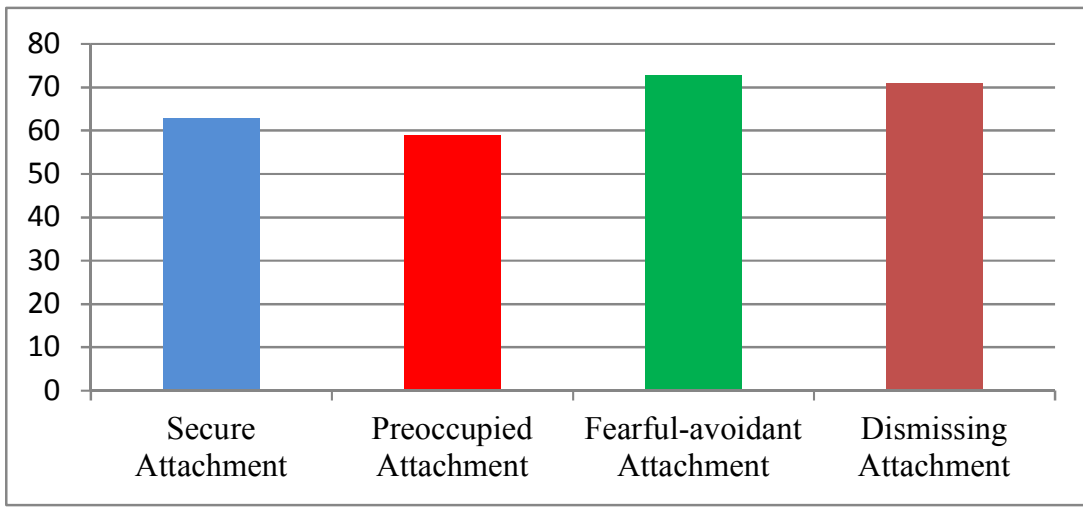

Berdasarkan pada gambar grafik di atas, dari 247 responden menunjukkan 73 responden pada dimensi gaya kelekatan fearful-avoidant attachment yang paling dominan, 71 responden pada dimensi gaya kelekatan dismissing attachment yang paling dominan, 63 responden pada dimensi gaya kelekatan secure attachment yang paling dominan dan 59 responden pada dimensi gaya kelekatan preoccupied attachment yang paling dominan.

\section{Uji Hipotesa Penelitian}

Berikut ini adalah tabel hasil uji korelasi kedua variabel penelitian:

Tabel 3. Uji Hipotesis

\begin{tabular}{lcc}
\hline \multicolumn{1}{c}{ Variabel } & Spearman Correlation & Sig. (2-tailed) \\
\hline Secure Attachment dan self-efficacy akademik & $0,130^{*}$ & 0,040 \\
Fearful-avoidant Attachment dan self-efficacy akademik & $-0,198^{* *}$ & 0,002 \\
Preoccupied Attachment dan self-efficacy akademik & $-0,034$ & 0,589 \\
Dismissing Attachment dan self-efficacy akademik & $-0,100$ & 0,115 \\
\hline
\end{tabular}

Berdasarkan hasil tabel 3, dimensi yang memiliki hubungan dengan selfefficacy akademik adalah dimensi gaya kelekatan secure attachment dan dimensi gaya kelekatan fearful-avoidant attachment. Pada dimensi gaya kelekatan secure attachment memiliki hubungan yang signifikan positif dengan self-efficacy akademik yang artinya apabila responden memiliki dimensi gaya kelekatan secure attachment yang tinggi maka self-efficacy akademiknya tinggi dan pada dimensi gaya kelekatan fearful-avoidant attachment memiliki hubungan yang signifikan negatif dengan self-efficacy akademik yang artinya apabila responden memiliki 
dimensi gaya kelekatan fearful-avoidant attachment yang tinggi maka selfefficacy akademik rendah. Dimensi yang tidak memiliki hubungan dengan selfefficacy akademik adalah dimensi gaya kelekatan preoccupied attachment dan dimensi gaya kelekatan dismissing attachment.

\section{Diskusi}

Pada hasil penelitian dimensi gaya kelekatan secure attachment memiliki hubungan yang positif dengan self-efficacy akademik sebesar $r=0,130$ dan nilai signifikansi $0,040(\mathrm{p}<0,005)$ dengan kekuatan hubungan yang tergolong sangat rendah (Sugiyono, 2011). Hubungan ini bersifat positif dengan artian semakin tinggi secure attachment semakin tinggi self-efficacy akademik siswa tersebut. Hasil penelitian sejalan dengan penelitian sebelumnya oleh Rachmawati dan Kristiana (2014) yang menunjukkan gaya kelekatan aman memiliki hubungan yang signifikan dengan self-efficacy akademik. Semakin tinggi dimensi gaya kelekatan secure attachment maka semakin tinggi self-efficacy akademik siswa. Hasil dari penelitian ini mungkin disebabkan dari gaya kelekatan secure attachment yang dilatarbelakangi oleh model of self yang positif terhadap dirinya dan model of other yang nyaman dalam menjalin hubungan interpersonal dengan orang lain (Bartholomew dan Horowitz, 1991). Sehingga ketika siswa tersebut berfikir positif terhadap dirinya dalam menyelesaikan tugas-tugas akademik, hal ini yang dapat menyebabkan self-efficacy akademik siswa tersebut tinggi. Siswa yang memiliki model of other positif ia akan merasa nyaman berada di lingkungan keluarga maupun disekolah, ini juga dapat menyebabkan self-efficacy akademik siswa tersebut tinggi. Ketika sekolah memiliki struktur pengajaran yang baik, maka siswa tidak akan kesulitan untuk belajar sehingga dapat meningkatkan selfefficacy akademik siswa. Jika dalam keluarga bersikap hangat, mengajarkan bagaimana menghadapi kesulitan, memberikan peran model yang positif, cepat tanggap dan ikut terlibat dalam mendukung perkembangan akademik, ini juga dapat meningkatkan self-efficacy akademik siswa.

Dimensi gaya kelekatan fearful-avoidant attachment memiliki hubungan yang negatif dengan self-efficacy akademik sebesar $r=-0,198$ dan nilai 
signifikansi $0,002(\mathrm{p}<0,005)$ dengan kekuatan hubungan yang tergolong sangat rendah. Hal ini menunjukkan semakin tinggi gaya kelekatan fearful-avoidant attachment semakin rendah self-efficacy akademik siswa tersebut. Hasil ini mungkin disebabkan dari gaya kelekatan fearful-avoidant attachment yang dilatarbelakangi oleh model of self meragukan diri sendiri dan model of other berfikir bahwa orang lain tidak menyukai dirinya dan merasa ketakutan jika ditinggalkan atau diabaikan (Bartholomew dan Horowitz, 1991). Siswa yang meragukan pada kemampuan dirinya dalam menyelesaikan tugas-tugas akademik, hal ini yang dapat menyebabkan menurunnya self-efficacy akademik siswa tersebut. Ketika siswa memiliki hubungan interpersonal yang negatif, tidak merasa nyaman berada di lingkungan keluarga maupun sekolah dengan berfikir bahwa orang lain tidak menyukai dirinya dan merasa takut jika diabaikan oleh orang lain, ini juga dapat menyebabkan self-efficacy akademik siswa tersebut rendah.

Selama proses penelitian, peneliti menyadari masih terdapat beberapa keterbatasan penelitian yang dapat menjadi bahan pertimbangan dan pengembangan penelitian berikutnya. Penelitian ini berupaya untuk mengukur gaya kelekatan pada siswa dengan memberikan kuesioner gaya kelekatan yang diisi langsung oleh siswa, hal ini memungkinkan dapat terjadinya penilaian subjektif pada saat pengisian kuesioner. Sementara itu, konstruk gaya kelekatan yang dikemukakan oleh Bartholomew dan Horowitz tidak hanya mengukur model of self namun juga model of others yang membutuhkan sudut pandang atau penilaian orang lain mengenai gaya kelekatan yang terbentuk.

Selain itu, Fraley, dkk (2015) mengemukakan bahwa setiap individu memiliki setiap dimensi gaya kelekatan, namun dimensi yang paling dominan akan berbeda sesuai dengan situasi yang sedang dihadapi. Pada penelitin ini, peneliti tidak mendeskripsikan secara jelas mengenai situasi spesifik (terkait pendidikan/bidang akademik) pada kuesioner gaya kelekatan. Hal ini diperkirakan dapat mempengaruhi persepsi responden dalam memberikan respon terhadap kuesioner gaya kelekatan. 


\section{Kesimpulan dan Saran}

Dimensi gaya kelekatan secure attachment memiliki hubungan positif dengan self-efficacy akademik dan dimensi gaya kelekatan fearful-avoidant attachment memiliki hubungan negatif dengan self-efficacy akademik. Dimensi gaya kelekatan yang tidak berhubungan dengan self-efficacy akademik adalah preoccupied attachment dan dismissing attachment.

Beberapa saran yang dapat berikan untuk pengembangan penelitian berikutnya, adalah:

a. Saran Teoritis

1. Pada penelitian selanjutnya, bisa mengkombinasikan metode yang lain seperti wawancara dan memberikan kuesioner pada signifikan others. Karena pada gaya kelekatan selain adanya konsep model of self juga adanya konsep model of other sehingga dapat dikombinasikan dengan wawancara kepada orangtua atau instasi sekolah agar lebih objektif.

2. Peneliti selanjutnya yang tertarik dengan topik yang sama disarankan untuk memperhatikan faktor-faktor lain yang diperkirakan juga dapat mempengaruhi self-efficacy akademik seperti: perubahan perkembangan, sekolah, keluarga, teman.

3. Peneliti selanjutnya yang menggunakan teori gaya kelekatan Bartholomew \& Horowitz, sebaiknya mendeskripsikan mengenai situasi yang dihadapi (seperti: setting akademis) pada saat melakukan pengukuran gaya kelekata agar lebih mengarahkan persepsi responden saat melakukan pengisian kuesioner.

b. Saran Praktis

1. Bagi orangtua, diharapkan dapat membantu untuk memberikan model of self positif dan model of others positif terhadap anak-anak mereka dengan begitu mereka akan merasa nyaman ketika berada di lingkungan keluarga maupun sekolah dan dapat menjalin hubungan interpersonal dengan orang lain yang dapat meningkatkan self-efficacy akademik siswa tersebut.

2. Bagi siswa, siswa hendaknya dapat mempertahankan keyakinan akan kemampuan akademiknya dengan memandang konsep model of self positif 
dan model of other positif dalam menghadapi atau menyelesaikan tugastugas akademik yang sedang dihadapi. Selain itu, siswa hendaknya untuk lebih berfikir positif akan kemampuan yang dimilikinya dan berfikir positif dalam menjalin kedekatan dengan orang lain seperti orangtua, teman sebaya, guru dan yang lainnya yang dapat meningkatkan selfefficacy akademik siswa tersebut.

3. Bagi Institusi Pendidikan, sebaiknya melakukan intervensi atau kegiatan yang terkait dengan self-efficacy akademik pada siswa SMA seperti menulis makalah. Hal ini untuk mengurangi pandangan model of self yang negatif pada siswa sehingga dapat memunculkan pandangan konsep model of self yang positif dan model of other yang positif yang dapat meningkatkan self-efficacy akademik.

\section{DAFTAR PUSTAKA}

Ainsworth, M.D.S. (1977). Attachment theory and it's utility in cross culture research. Dalam leiderman, P.H: Tulkin, S.S and Rasenfeld, A. Culture and Infancy. New York: Academic Press.

Bandura, A. (1997). Self Efficacy: The Excercise of Control. New York: W. H Freeman and Company.

Bartholomew, K. \& Horowitz. (1991). Attachment styles among young adults: a test of a four category model. Journal of Personality and Social Psychology, 61 (2): 226-224

Dwitantyanov, A., Hidayati, F., Sawitri D. R. (2010). Pengaruh pelatihan berpikir positif pada efikasi diri akademik mahasiswa (studi eksperimen pada mahasiswa fakultas psikologi Undip semarang. Jurnal Vol. 8, No.2. Oktober. Jurnal Psikologi Undip. Semarang: Universitas Diponegoro.

Ferla, J., dkk. (2007). Academic Self-Efficacy and Academic Self-Concept: Reconsidering Structural Relationship. h.1-25.

Fraley., dkk. (2015). Are Adult Attachment Styles Categorical or Dimensional? A Taxometric Analysis of General and Relationship-Specific Attachment Orientations. Journal of Personality and Social Psychology. 
Hofstra, J., \& Van, O. J. P. (2014). Ontwikkeling en evaluatic van de Hechtingsstijlvragenlijst (HSL) (Development and Evaluating of the Attachment Style Questionnaire (ASQ). Nederlands Tijdschrift voor de psychologic, 58, 95-102.

Nugrahani, U. P. (2010). Hubungan Antara Persepsi Terhadap Tugas Akademik Dan Atraksi Interpersonal Siswa Terhadap Guru Dengan Motivasi Belajar Pada Siswa Program Rintisan Sekolah Bertaraf Internasional (Sma Negeri 7 Purworejo). Skripsi. Semarang: Universitas Diponegoro.

Rachmawati, A. Y., Kristiana, I. F. (2014). Hubungan antara kelekatan aman dengan efikasi diri akademik remaja. Jurnal Vol.3 No.4 page 30-41. Fakultas Psikologi. Semarang: Universitas Diponegoro.

Rauf. N. W. (2015). Hubungan Antara Academic Self Efficacy Dan Kecenderungan Mengalami Academic Burnout Pada Mahasiswa Serta Tinjauannya Menurut Agama Islam. Skripsi. Fakultas Psikologi. Jakarta: Universitas Yarsi.

Santrock, J. W. (2011). Life-span development (13th ed). New York: McGrawHill.

Schunk, D. H., \& Meece, J. L. (2006). Self-efficacy development in adolescence. In F. Pajares \& T. Urdan (Eds.), Self-efficacy beliefs of adolescents (pp.71-96). Greenwich: Informational Age Publishing, Inc.

Sugiyono. (2011). Statistika untuk Penelitian. Bandung: Alfabeta.

Woolfolk, A. E. 1990. Educational Psychology Fourth Edition. New Jersey: Prentice-Hall, Inc.

Zajacova, A., Scott M. L. \& Thomas J. E. (2005) Self-Efficacy, Stress, And Academic Success In College. Research In Higher Education, Volume 46, No. 6. 